\title{
Modification of Staged Embolization-Hysterectomy Procedure for Placenta Accreta to Avoid Non-Target Embolisation of Ovaries
}

\author{
Catherine L Davis ${ }^{1^{*}}$ D, Bishoy Hanna ${ }^{2}$, John Keogh ${ }^{3}$, Eisen Liang ${ }^{4}$ and Amir Hanna ${ }^{3}$ \\ ${ }^{1}$ Department of Obstetrics and Gynaecology, Nepean Blue Mountains Local Health District, Australia \\ ${ }^{2}$ Northern Sydney Local Health District, Australia \\ ${ }^{3}$ Department of Obstetrics and Gynaecology, Sydney Adventist Hospital Clinical School, University of Sydney, \\ Australia \\ ${ }^{4}$ Department of Radiology, Sydney Adventist Hospital Clinical School, University of Sydney, Australia
}

*Corresponding author: Dr. Catherine L Davis, Department of Obstetrics and Gynaecology, Nepean Blue Mountains Local Health District, Australia, Tel: +61-448-126-392

\begin{abstract}
Placenta accreta spectrum describes the abnormal adherence of the placenta to, into or beyond the myometrium of the uterus. Three women who were antenatally diagnosed with placenta accreta underwent a modified staged embolization-hysterectomy procedure consisting of; placement of prophylactic bilateral common iliac artery occlusion balloons, a classical caesarean section, surgical dissection of the ovaries from the uterus, embolization of the uterine arteries, followed by hysterectomy. The three operations proceeded without complication. This simple modification of dissecting the ovaries from uterus shortens embolization procedure and completely prevents inadvertent particle embolization of ovaries from ovarian arteries or utero-ovarian collateral vessels.
\end{abstract}

\section{Keywords}

Placenta accreta, Hysterectomy, Caesarean section, Embolization, Prevention

\section{Introduction}

Placenta accreta spectrum (PAS), also known as morbidly adherent placenta, is a rare disorder of placental adherence with high maternal and neonatal morbidity and mortality [1]. Placenta accreta is histologically characterised by attachment of the placenta to the myometrium without intervening decidua basalis [2]. Invasion of the chorionic villi into the myometrium is termed placenta increta, while invasion of the placental villi through the serosa is termed placenta percreta [1]. The greatest risk factor for PAS disorders is uterine scarring from surgical procedures, particularly caesarean section [2]. With an increase in the caesarean section rate, we have seen a corresponding increase in the rate of this morbid condition.

The high morbidity and mortality associated with PAS is due to massive haemorrhage at the time of delivery due to partial placenta separation and due to enlarged aberrant surface vessels [2]. For the mother, catastrophic haemorrhage can require blood products, intensive care unit admission and lead to hysterectomy, disseminated intravascular coagulation, multiorgan failure, and death [1]. In placenta percreta, invasion into the bladder imposes a high risk of renal tract injuries and fistula formation at time of surgery [3]. With such high morbidity, optimisation of surgical management is essential to improving patient outcomes.

Several surgical techniques have been described for the management of this condition [3,4]. Angstmann, et al., describe a staged procedure of a classical caesarean section, immediately followed by uterine artery embolization with interventional radiology and subsequent hysterectomy. This technique significantly decreases blood loss compared to traditional caesarean hysterectomy [4] and has thus been utilised and modified by many teams worldwide [5].

Citation: Davis CL, Hanna B, Keogh J, Liang E, Hanna A (2020) Modification of Staged Embolization-Hysterectomy Procedure for Placenta Accreta to Avoid Non-Target Embolisation of Ovaries. Obstet Gynecol Cases Rev 7:188. doi.org/10.23937/2377-9004/1410188

Accepted: December 19, 2020: Published: December 21, 2020

Copyright: (C) 2020 Davis CL, et al. This is an open-access article distributed under the terms of the Creative Commons Attribution License, which permits unrestricted use, distribution, and reproduction in any medium, provided the original author and source are credited. 


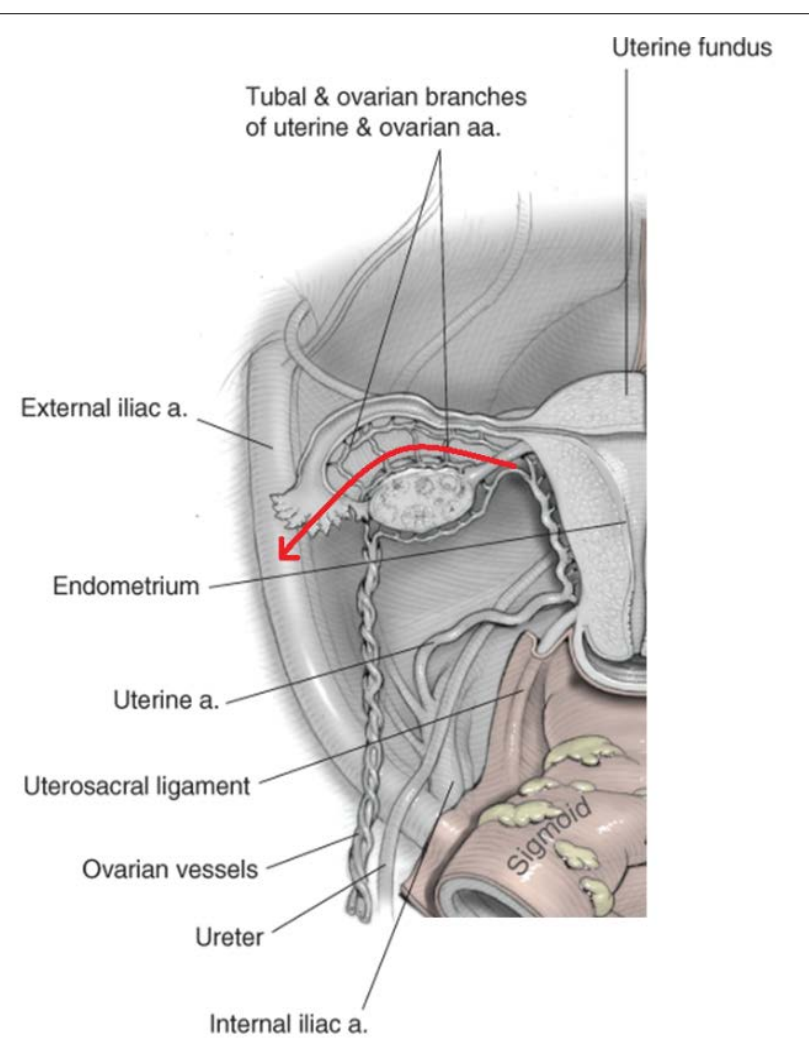

Figure 1: Blood supply of the uterus, fallopian tube and ovary. Red arrow indicates line of dissection via mesosalpinx and suspensory ligament of the ovary. Adapted from 'Anatomy' [6].

Here we describe an innovative but simple addition to this technique which involves surgical ovarian isolation. This is performed with the aim to decrease the risk of premature menopause from non-target embolization of the ovaries. We report our experience of this technique with three women who were antenatally diagnosed with placenta accreta.

\section{Case Description}

We report a retrospective case series of three women, operated on by two obstetric surgeons as part of a multidisciplinary team involving anaesthetists, interventional radiologists, intensive care physicians and neonatologists.

The staged procedure is outlined as follows:

Bilateral prophylactic common iliac artery occlusion balloons were inserted, as a contingency measure in the event of catastrophic haemorrhage at caesarean section. This was performed under local anaesthetic, with ultrasound guided femoral puncture and minimal use of fluoroscopy and X-ray contrast. An arterial line, a central venous line and large-bore cannulae are inserted. An indwelling catheter is inserted into the bladder. General anaesthesia is administered, and the patient is prepped and draped.

The obstetrician performs a midline abdominal incision. Classical caesarean is performed to avoid the placenta, with efficient delivery of infant and cord clamping. No attempt is to be made to separate the placenta; it is left in situ and the uterus is closed. No catastrophic haemorrhage was encountered in these three cases and therefore the common iliac occlusion balloons did not need to be inflated to control haemostasis. The ovaries are then dissected away from the uterus by division of mesosalpinx and suspensory ligament of the ovary (Figure 1). Haemostasis is ensured and the abdomen is closed [6].

Following caesarean section, the patient is transferred to the angiography suite. Uterine embolization was performed, including bilateral uterine arteries and any other pelvic collateral arteries deemed to be supplying the uterus/placenta.

The patient is transferred back to the operating suite for a total or subtotal hysterectomy. At the end of the hysterectomy, the woman is transferred routinely to the intensive care unit for 24 hours of observation. Cell saver was used in the hysterectomy portion only of the procedure for all cases.

Three women, all aged 35 years, had a finding of placenta accreta on routine antenatal sonography from 2015-2016. There was no ultrasonographic evidence of bladder involvement in any case. All women had previous uterine surgery with two of the women each having three previous lower segment caesarean sections (LSCS), while the third had one previous caesarean in addition to six curettage procedures (Table 1). All patients had admissions during the pregnancy for antepartum haemorrhage. There were no other comorbidities in these patients. The patients required delivery at 34 to 36 weeks gestation due to antepartum haemorrhage (APH).

The operations for the three patients proceeded as planned. Cell saver was used in each case. No patient required a blood transfusion, patient 2 had an iron infusion (Table 2). No one required reoperation.

\section{Conclusions}

Placenta accreta spectrum is an increasingly prevalent morbid condition [2] and thus requires further study to optimise management and therefore patient outcomes. A history of previous uterine surgery, particularly caesarean section is known to be the largest risk factor for placenta accreta, [2] which is reflected in the three patients described here with a history of multiple uterine operations (Table 1). The incidence of PAS increases with the number of previous caesareans, with a significant increased risk with a history of three or more caesarean sections [7]. Patient's 1 and 3 had three previous LSCS. While the second patient had just one previous LSCS, she had six dilatation and curettages and one myomectomy, increasing her risk of uterine scarring and abnormal placental adherence.

Optimal management of placenta accreta remains controversial. Many techniques have been described but all assume antenatal diagnosis which allows for 
Table 1: Summary of antenatal patient demographics.

\begin{tabular}{|c|c|c|c|}
\hline Patient & 1 & 2 & 3 \\
\hline Age & 35 & 35 & 35 \\
\hline Gravida & 4 & 9 & 5 \\
\hline Parity & 3 & 1 & 4 \\
\hline Mode of delivery & $\begin{array}{l}\text { 1x emergency LSCS }{ }^{\dagger} \text { and } \\
\text { 2x elective LSCS }\end{array}$ & $1 \times \operatorname{LSCS}$ & $1 \times N^{\prime} D^{\ddagger}, 3 x$ LSCS \\
\hline Other previous uterine surgery & Nil & $6 x \mathrm{D} \& \mathrm{C}^{\S}, 1$ myomectomy & Nil \\
\hline PMHx & Nil & Nil & Nil \\
\hline APH & $\begin{array}{l}\text { At } 20+1-\text { admitted to } \\
\text { hospital }\end{array}$ & Yes - 31/40 & $\begin{array}{l}\text { Yes, 12/40. 18/09. And at } 33+5 \\
250 \mathrm{ml} \mathrm{APH} .+200 \mathrm{ml}\end{array}$ \\
\hline Gestational age at delivery & 34 & 36 & 34 \\
\hline Singleton & Yes & Yes & Yes \\
\hline
\end{tabular}

†LSCS: Lower uterine segment caesarean section; ‘NVD: Normal vaginal delivery; §D\&C: Dilatation and curettage.

Table 2: Surgical outcomes.

\begin{tabular}{|c|c|c|c|}
\hline Patient & 1 & 2 & 3 \\
\hline Blood loss $^{\dagger}$ & $1000 \mathrm{ml}$ & $800 \mathrm{ml}$ & $600 \mathrm{ml}$ \\
\hline Iron infusion? & No & Yes & No \\
\hline Days in ICU & 2 & 1 & 1 \\
\hline $\begin{array}{l}\text { Duration postpartum hospital stay } \\
\text { (operation to discharge) }\end{array}$ & 7 & 5 & 5 \\
\hline Pathology & $\begin{array}{l}\text { Placenta increta, Normal cord } \\
\text { insertion }\end{array}$ & $\begin{array}{l}\text { Placenta percreta. Grade } 4 \\
\text { placenta praevia and vasa } \\
\text { praevia. }\end{array}$ & $\begin{array}{l}\text { Placenta percreta. High } \\
\text { grade previa. Normal cord } \\
\text { and membranes }\end{array}$ \\
\hline
\end{tabular}

†Note: Use of cell saver.

planned delivery which is associated with less blood loss [3]. The staged embolization-hysterectomy procedure has previously been shown to decrease blood loss, need for blood transfusion and number of units transfused [4]. The three women analysed in the present study had minimal blood loss, did not require a transfusion and had uneventful recoveries with this technique (Table 2). The addition of detachment of the ovaries from the uterus, prior to embolization, allows ovarian protection without any marked change in estimated blood loss or complications compared to previous studies [4].

Embolization prior to hysterectomy allows for a clear surgical field enabling more precise surgical technique [4], yet there is mounting concern that it poses a risk of premature ovarian failure [8]. Effective uterine embolization in the settings of post-partum haemorrhage and prior to hysterectomy for placenta accreta requires devascularising the uterus by shutting down not only bilateral uterine arteries but all other potential supplies including the bilateral ovarian arteries and other pelvic collaterals. By surgically isolating ovaries from the uterus, our modification not only shortens the embolization procedure, but also protects the ovaries from non-target particle embolization of the ovarian artery or utero-ovarian collateral arteries. There is a small risk of non-target particle embolization of the ovaries via utero-ovarian collaterals [7], although the flow is more likely to be away from ovaries towards the gravid uterus.
Uterine artery embolization in the setting of primary postpartum haemorrhage can occasionally result in ovarian failure [9], including in women with alterations in anatomy [10]. Furthermore, embolization in the context of uterine fibroids has been associated with amenorrhoea, menopausal symptoms and biologic ovarian failure in up to $2 \%$ of women less than 45 years [11]. While fertility preservation is not relevant to our patients, the emotional impact of premature menopause and physical effects on cardiovascular health, osteoporosis can be severe and should not be dismissed [12].

In conclusion, we report a simple yet novel method of ovarian isolation before embolization and caesarean hysterectomy for placenta accreta. This has the potential to reduce the risk of premature ovarian failure due to inadvertent embolization of ovarian supply, with no known harms. This technique has been demonstrated on three women with promising results.

\section{Disclosure}

No funding to disclose.

\section{Conflicts of Interest}

None.

\section{Statement of Equal Contribution}

$\mathrm{AH}$ and JK were the primary surgeons who developed the technique, performed the surgery and collated the 


\section{patient records.}

EL contributing to the conception of the technique, actively involved in the clinical management, literature review and critically revising the draft.

\section{$\mathrm{BH}$ collated patient data.}

$C D$ reviewed the literature, analysed the data and produced the initial report.

All Authors edited the final report.

\section{Acknowledgements}

We thank Dr. Tanya Nippita for comments on the manuscript.

\section{References}

1. Silver RM, Branch DW (2018) Placenta accreta spectrum. N Engl J Med 378: 1529-1536.

2. Jauniaux E, Gronbeck L, Bunce C, Langhoff-Roos J, Collins SL (2019) Epidemiology of placenta previa accreta: A systematic review and meta-analysis. BMJ Open 9: e031193.

3. Grace Tan SE, Jobling TW, Wallace EM, McNeilage LJ, Manolitsas T, et al. (2013) Surgical management of placenta accreta: A 10-year experience. Acta Obstet Gyn Scan 92: $445-450$.

4. Angstmann T, Gard G, Harrington T, Ward E, Thomson A, et al. (2010) Surgical management of placenta accreta: A cohort series and suggested approach. Am J Obstet Gynecol 202: 38.e1-38.e9.
5. Cesar H, Ricardo D-Monaco, Gustavo, Marina L, Jorge J, et al. (2019) Non-conservative management of placenta accreta spectrum in the hybrid operating room: A retrospective cohort study. Cardio Vasc Intervent Radiol 42: 365-370.

6. Hoffman BL SJ, Halvorson LM, Hamid CA, Corton MM, Schaffer JI (2020) Anatomy. Williams Gynecology.

7. Marshall NE, Fu R, Guise JM (2011) Impact of multiple cesarean deliveries on maternal morbidity: A systematic review. Am J Obstet Gynecol 205: 262.

8. Mohr-Sasson A, Spira M, Rahav R, Dafna M, Eyal S, et al. (2018) Ovarian reserve after uterine artery embolization in women with morbidly adherent placenta: A cohort study. PLoS One 13: e0208139.

9. Kim T-H, Lee H-H, Kim J-M, Ryu A-L, Chung S-H, et al. (2013) Uterine artery embolization for primary postpartum hemorrhage. Iran J Reprod Med 11: 511-518.

10. Elsarrag SZ, Forss AR, Richman S, Salih SM (2015) Acute ovarian insufficiency and uterine infarction following uterine artery embolization for postpartum hemorrhage. Clin Med Rev Case Rep.

11. Walker WJ, Pelage JP (2002) Uterine artery embolisation for symptomatic fibroids: Clinical results in 400 women with imaging follow up. BJOG 109: 1262-1272.

12. Faubion SS, Kuhle CL, Shuster LT, Rocca WA (2015) Long-term health consequences of premature or early menopause and considerations for management. Climacteric 18: 483-491. 